\title{
BANCO DE DADOS RELACIONAL PARA CADASTRO, AVALIAÇÃO E MANEJO DA ARBORIZAÇÃO EM VIAS PÚBLICAS ${ }^{1}$
}

\author{
Demóstenes Ferreira da Silva Filho², Patrícia Unger César Pizetta ${ }^{3}$, João Batista Salmito Alves de Almeida ${ }^{4}$, \\ Kathia Fernandes Lopes Pivetta ${ }^{5}$ Antônio Sérgio Ferraudo ${ }^{6}$
}

\begin{abstract}
RESUMO - A arborização urbana em calçadas é fundamental para manutenção da qualidade de vida, proporcionando conforto aos habitantes das cidades. Contudo, existem problemas causados principalmente pela falta de planejamento na implantação e no manejo da arborização. O objetivo do presente trabalho foi a criação de um banco de dados relacional para auxiliar no cadastro informatizado, na avaliação e no manejo da arborização de vias públicas. Apresenta resultados sobre a valoração de indivíduos cadastrados, cálculo da diversidade entre os bairros, introdução de fotos digitais e relatórios para manejo em interface amigável, podendo servir de instrumento à manutenção da arborização e de vetor de comunicação para educação ambiental.
\end{abstract}

Palavras-chave: Banco de dados relacional, arborização urbana e educação ambiental.

\section{RELATIONAL DATABASE FOR INVENTORY SYSTEM EVALUATION AND MANAGEMENT OF URBAN STREET TREES}

\begin{abstract}
Urban street trees are is important for maintaining life quality and providing comfort to city dwellers. However, many problems occur caused mainly by lack of planning in the installation and management planning. This work aimed to create a relational database to help with a computerized urban street tree inventory system, evaluation and management. It presents results on individual tree value calculation, neighborhood diversity, introduction of digital photos and reports on friendly interface management, thus acting as a tool for street tree planting maintenance and a communication vector for environmental education.
\end{abstract}

Key words: Relational database, urban tree planting and environmental education.

\section{INTRODUÇÃO}

A arborização urbana atua sobre o conforto humano no ambiente por meio das características naturais das árvores, proporcionando sombra para pedestres e veículos, redução da poluição sonora, melhoria da qualidade do ar, redução da amplitude térmica, abrigo para pássaros e equilíbrio estético, que ameniza a diferença entre a escala humana e outros componentes arquitetônicos como prédios, muros e grandes avenidas.

Entretanto, em muitas situações o planejamento urbano deixa de incluir a arborização como equipamento

1 Recebido para publicação em 6.12.2001.

Aceito para publicação em 6.11.2002.

Parte da dissertação de mestrado do primeiro autor, intitulada: Cadastro informatizado da arborização de vias públicas do município de Jaboticabal-SP.

2 Mestrando do Curso de pós-graduação em Agronomia, Faculdade de Ciências Agrárias e Veterinária da Universidade Estadual Paulista - FCAV/UNESP, Via de Acesso Prof. Paulo Donato Castellane, s/n, 14.884-900 Jaboticabal-SP, bolsista do CNPq, $<$ demostenes@metalnet.com.br>; ${ }^{3}$ Mestranda do Curso de pós-graduação em Agronomia, FCAV/UNESP, bolsista da FAPESP, <patyclo@fcav.unesp.br>; ${ }^{4}$ Mestre pelo Curso de pós-graduação em Agronomia, FCAV/UNESP, bolsista CAPES, $<$ jbsalmito@hotmail.com.br>; ${ }^{5}$ Prof ${ }^{\text {a }}$. Dra ${ }^{\mathrm{a}}$. do Dep. de Produção Vegetal, FCAV/UNESP, <kathia@fcav.unesp.br>; ${ }^{6}$ Prof. Dr. do Dep. de Ciências Exatas, FCAV/UNESP, <ferraudo@fcav.unesp.br>. 
a ser devidamente planejado, permitindo, muitas vezes, que iniciativas particulares pontuais e desprovidas de conhecimento técnico atualizado tomem espaço com plantios irregulares de espécies sem compatibilidade com o planejamento anterior. Esta situação é traduzida em perda da eficácia da arborização em transmitir conforto físico e psíquico, trazendo infortúnios e transtornos. Esse procedimento é muito comum nas cidades brasileiras, causando, muitas vezes, sérios prejuízos, como rompimento de fios de alta-tensão, interrupções no fornecimento de energia elétrica, entupimento em redes de esgoto, obstáculos para circulação e acidentes envolvendo pedestres, veículos ou edificações.

Em função do grande volume de informações necessárias ao adequado manejo da arborização, é indispensável que elas estejam organizadas por meio de um sistema computadorizado (Takahashi, 1992).

Segundo Kaufeld (1996), o modelo de banco de dados relacional possui a capacidade de lidar com grandes volumes de informações, eliminando dados redundantes. No modelo relacional existe a possibilidade de elaboração de um relacionamento lógico entre as informações referentes à espécie e as referentes ao indivíduo, evitando-se a necessidade da repetição de informações e agilizando as consultas feitas às duas fontes de dados.

Com base em Dalcin (1994), na prática, o modelo relacional oferece os seguintes benefícios:

a) simplicidade e uniformidade (o modelo relacional é compacto);

b) independência dos dados físicos;

c) interfaces de alto nível para usuários finais;

d) visões múltiplas dos dados;

e) melhoria na segurança dos dados;

f) redução significativa do tempo gasto na manutenção da base de dados; e

g) possibilidade de expansão devido à flexibilidade do sistema.

Milano \& Dalcin (2000) discorreram sobre métodos de avaliação de indivíduos arbóreos, apresentando o método norte-americano mais utilizado. Consistia em aprimorações do método Felt, que em 1975 foi transformado na "Cartela de Avaliação de Árvores" da Michigan Forest and Park Association, sendo ainda hoje utilizado naquele estado americano. Paralelamente, a Conferência

R. Árvore, Viçosa-MG, v.26, n. 5, p.629-642, 2002
Nacional sobre Árvores Urbanas de 1951 estabeleceu também um método de avaliação que adotava o valor de referência de US\$ 5.00 por polegada quadrada de área transversal do tronco, cujas sucessivas revisões elevaramno para US\$ 9.00 por polegada quadrada em 1969. Utilizando o valor de US\$ 10.00 por polegada quadrada transversal de tronco como referência, multiplicado pelas variáveis espécie, localização e condição da árvore, em 1975, esse método foi compilado no "Guia para Avaliação Profissional de Árvores e Arbustos Ornamentais", amplamente utilizado em todo o País até hoje. Esses métodos estabelecem o valor básico da árvore em função de um valor fixo por polegada quadrada (US\$10.00, por exemplo), ao qual são aplicados sucessivamente "índices" ou "fatores" detratores.

O objetivo deste trabalho foi a criação de banco de dados relacional para auxiliar no cadastro, na avaliação e no manejo da arborização de vias públicas por meio da elaboração de interface amigável e de fórmulas computacionais para avaliação de indivíduos, distribuição e diversidade das espécies nos bairros e na totalidade da cidade.

\section{MATERIAL E MÉTODOS}

\subsection{Descrição do Local de Estudo}

O estudo foi realizado na cidade de Jaboticabal, município do Estado de São Paulo, cuja população atual é de 62.774 habitantes (IBGE, 2000).

O município de Jaboticabal possui área de $704 \mathrm{~km}^{2}$, altitude de $595 \mathrm{~m}$ acima do nível do mar e coordenadas $21^{\circ} 15^{\prime} 20^{\prime \prime}$ de latitude e $48^{\circ} 19^{\prime} 16^{\prime \prime}$ de longitude e 1,22 de taxa de crescimento anual (Seade, 1999).

O clima, de acordo com a classificação de Köppen, é Cwa, subtropical, com chuvas de verão e inverno relativamente seco. O período de maior intensidade de calor é de dezembro a fevereiro e o de maior intensidade de frio, de junho a julho.

A arborização das vias públicas foi objeto de estudo de Graziano et al. (1987), que constataram ser à espécie Ocotea pulchella (canelinha) predominante, com 43\% dos indivíduos, seguida de Caesalpinia peltophoroides (sibipiruna), Michelia champaca (magnólia-amarela) e Terminalia catappa (chapéu-de-sol). Foram encontradas 59 espécies, com dez espécies mais freqüentes perfazendo $90,20 \%$ do total de indivíduos, o que demonstra baixa eqüitabilidade. 
A pesquisa atual abordou a elaboração de banco de dados e cadastro da arborização nas vias públicas da área urbana, incluindo o centro e outros 32 bairros da cidade, não considerando praças, distritos municipais e condomínios fechados.

\subsection{Descrição dos Atributos}

No Quadro 1 pode-se notar a definição das informações sistematizadas para serem coletadas nas vias públicas, utilizando-se de atributos definidos com base nos trabalhos de Thurman (1983) e Dalcin (1992a).

Os itens considerados subjetivos, que podem mudar de acordo com cada observador, serão descritos a seguir. Os demais foram considerados auto-explicativos.
A Figura 1 foi dividida em cinco partes:

I - Localização e Identificação;

II - Dimensões;

III - Biologia;

IV - Entorno e Interferências; e

V - Definição de ações

\section{I - Localização e Identificação}

Nesta parte são marcados os nomes da rua e o número do imóvel onde se encontra a árvore, o bairro, o nome da árvore e a largura da rua e calçada.

Quadro 1 - Tela de coleta manual

Table 1 - Manual collection screen

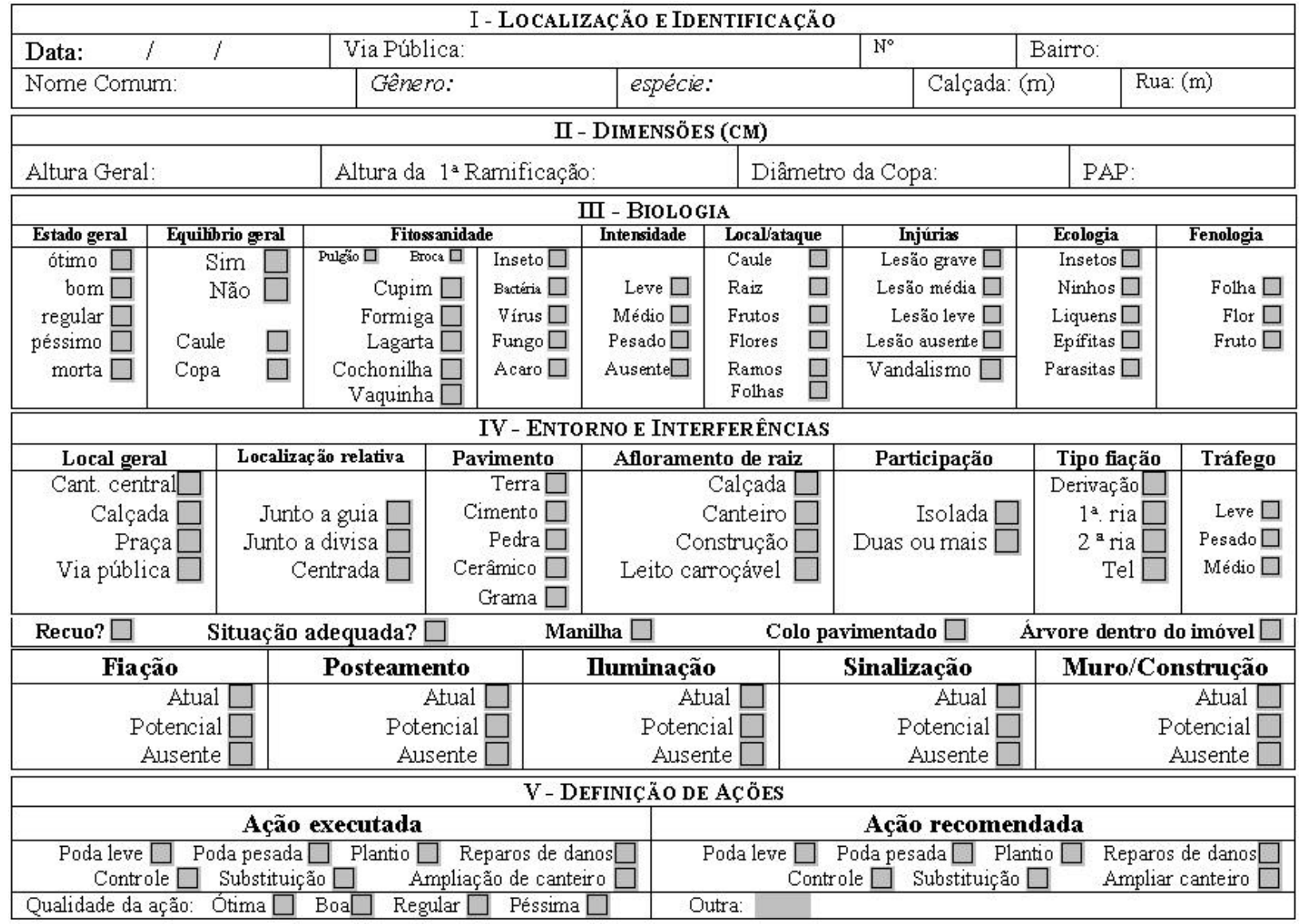




\section{II - Dimensões}

São anotadas as medições da árvore: altura geral, altura da primeira ramificação, diâmetro da copa e perímetro à altura do peito ( $\mathrm{PAP})$.

\section{III - Biologia}

Itens relativos à avaliação do espécime vegetal.

\section{Estado geral (condição):}

Ótimo - árvore vigorosa e sadia; sem sinais aparentes de ataque de insetos, doenças ou injúrias mecânicas; pequena ou nenhuma necessidade de manutenção; forma ou arquitetura característica da espécie.

Bom-médias condições de vigor e saúde; necessita de pequenos reparos ou poda; apresenta descaracterização da forma: apresenta sinais de ataque de insetos, doença ou problemas fisiológicos.

Regular - apresenta estado geral de início de declínio; apresenta ataque severo por insetos, doença ou injúria mecânica, descaracterizando sua arquitetura ou desequilibrando o vegetal; problemas fisiológicos requerendo reparo.

Péssimo - avançado e irreversível declínio; apresenta ataque muito severo por insetos, doença ou injúria mecânica, descaracterizando sua arquitetura ou desequilibrando o vegetal; problemas fisiológicos cujos reparos não resultarão em benefício para o indivíduo.

Morta - árvore seca ou com morte iminente.

Equilíbrio geral: quando a árvore possui caule reto e copa de mesmas proporções para todos os lados.

Fitossanidade: assinalando-se o nome vulgar do causador do ataque, são listados os tipos mais comuns.

Intensidade: (de fitossanidade).

Leve - quando o organismo ou agente está presente, porém sem causar danos à árvore.

Médio - quando o organismo ou agente está presente, causando danos reparáveis à árvore.

Pesado - quando o organismo ou agente está causando danos graves, que podem levar a árvore a um declínio irreversível.

Local ataque: exibe a parte da árvore afetada ou injuriada para ser assinalada.

R. Árvore, Viçosa-MG, v.26, n.5, p.629-642, 2002
Injúrias: assinalou-se o grau da injúria e se ela foi causada por vandalismo.

Lesão grave - quando a lesão compromete a sobrevivência da árvore.

Lesão média - quando a injúria é considerável, mas a árvore pode ser recuperada mediante ações de controle.

Lesão leve - quando a injúria é de pequena proporção e a árvore pode promover a recuperação sem qualquer auxílio.

\section{IV - Entorno e Interferências}

\section{Localização relativa}

Junto à guia - quando a árvore está localizada próximo da guia da calçada.

Centrada - quando a árvore está localizada no centro da calçada.

Junto à divisa - quando a árvore está localizada próximo do muro ou da cerca do imóvel.

Tráfego: o grau de tráfego apresentado;

Leve - poucos veículos (de 0 a 10) passaram na via pública durante o momento de cadastro na rua.

Médio - quando alguns veículos (de 10 a 20) passaram na via pública durante o momento de cadastro.

Pesado - quando mais de 20 veículos passaram na via pública durante o momento do cadastro.

\section{Participação na paisagem}

Isolada - quando a árvore estiver isolada como representante único da espécie no local.

Duas ou mais - quando um ou mais indivíduos da mesma espécie estiverem próximos.

Situação adequada? - quando a árvore está bem no local, em relação a conflitos com outros equipamentos ou construções.

Com relação aos itens Fiação, Posteamento, Iluminação, Sinalização e Muro/Construção:

Atual - quando o equipamento urbano ou edificação está em contato com alguma parte da árvore.

Potencial - quando a espécie, pelo seu crescimento normal, vai entrar em contato com algum equipamento ou edificação. 
Ausente - quando não existir possibilidade de contato.

\section{V - Definição de ações}

Quando foi observada alguma atividade de poda leve, poda pesada, reparos de danos, substituição ou ampliação de canteiro e qualificação dessa ação, ou quando existiu a necessidade de recomendação de ação.

\section{Qualidade da ação:}

Ótima - ação correta, necessária para adequada manutenção da árvore, executada com técnica.

Boa - ação correta, porém sem técnica.

Regular - ação executada sem a observância de normas técnicas, porém sem causar danos graves.

Péssima - ação incorreta, com conseqüências graves para a árvore.

\subsection{Fórmulas Computacionais}

\subsection{1. Índice de Importância Relativa (Iir)}

A determinação do índice de importância relativa (Iir) é baseada em Dalcin (1992b), sendo a expressão completa como segue:

$$
\text { Iir }=(\text { Ve } x \text { Ve } x \text { Vl x Vbm }) / \text { freq }
$$

em que $\mathrm{Ve}=$ valor da espécie; $\mathrm{Vc}=$ valor de condição (estado geral); $\mathrm{Vl}=$ valor de localização; $\mathrm{Vbm}=$ valor biométrico; freq = freqüência da espécie na arborização; descrição das variáveis;

\section{A) Valor da espécie (Ve)}

A variável Ve é o valor da espécie, extraído por meio do relacionamento com a tabela de espécies (contendo os dados com as avaliações de todas as espécies arbóreas utilizadas na arborização), Figura 5, sendo expresso da seguinte maneira:

$$
\begin{aligned}
\mathrm{Ve} & =(\text { Disponibilidade }+ \text { Partes desejáveis } \\
& + \text { Desenvolvimento }+ \text { Adaptabilidade }) / 4
\end{aligned}
$$

Categorizando-se as variáveis do dividendo em valores de até 4 , obtêm-se 16 categorias com intervalos de 0,25 .
Nestas variáveis, os valores possíveis foram definidos da seguinte maneira:

\section{Disponibilidade}

4 - Não encontrada no mercado, e, ou, técnicas de reprodução desconhecida ou não-iniciadas.

3 - Encontrada com dificuldade; reprodução difícil.

2 - Encontrada com facilidade.

1 - Mudas no local ou disponíveis na quantidade desejada.

Dessa forma atribui-se a nota máxima à espécie de maior dificuldade de reposição, contra uma nota mínima da espécie prontamente disponível (Dalcin, 1992b).

\section{Partes desejáveis}

4 - Flores, frutos, folhas, ramos e raízes desejáveis.

3 - Uma das partes indesejável.

2 - Duas das partes indesejáveis.

1 - Três ou mais partes indesejáveis.

Essa variável procura representar características morfológicas inerentes da espécie, ressaltando aquela que possuir melhores características para o ambiente (Dalcin, 1992b).

\section{Desenvolvimento}

4 - Muito lento.

3 - Lento.

2 - Normal.

1 - Rápido.

Segundo o autor, uma espécie com crescimento muito lento possui maior valor acumulado que outra de mesmo diâmetro à altura do peito (DAP) de crescimento rápido, pois sua reposição se dá em um maior intervalo de tempo. Desta maneira, procura-se captar com esta variável o valor acumulado.

\section{Adaptabilidade}

4 - Difícil adaptação: muito exigente

3 - Espécie exigente

2 - Espécie adaptada

1 - Nativa ou invasora

R. Árvore, Viçosa-MG, v.26, n.5, p.629-642, 2002 
Essa variável procura definir o grau de adaptação da espécie ao ambiente imposto. Portanto recebe nota máxima a espécie de difícil adaptação, contra nota mínima para a espécie sem problemas aparentes de adaptação; está sendo avaliada uma espécie para cada árvore já estabelecida na arborização.

\section{B) Valor de condição (Vc)}

Vc $=$ Valor de condição, com cinco variáveis: indivíduo ótimo $=4$, bom $=3$, regular $=2$, péssimo $=1$, morto $=0$. Pormenorizado no item 2.2. (III)

\section{C) Valor de localização (VI)}

$\mathrm{Vl}$ = Valor de localização, com três variáveis:

- presença (1) ou ausência (0) de outro ou mais indivíduos da mesma espécie ao lado ou próximo;

- presença (1) ou ausência (0) de recuo na construção; e

- presença (1) ou ausência (0) de adequação. A ausência de adequação refere-se a qualquer impedimento físico que obrigue procedimentos de manutenção, como podas drásticas ou reformas onerosas.

A presença de outro indivíduo da mesma espécie pode acrescentar valor paisagístico ao ambiente, pela ação do conjunto, muito embora uma árvore isolada em uma rua possa ser também mais bem avaliada pela sua raridade naquele espaço.

Cada uma destas alternativas tem nota 1 na resposta afirmativa; caso todas sejam negativas a nota final será 1, pois não poderá existir valor igual a zero no valor de localização, para evitar que o índice final seja zero, o que inviabilizaria o modelo. Quando todas as variáveis forem negativas e a nota final, para este item, for igual a 1, a multiplicação por 1 não alterará os demais valores do índice de valor de importância. Desta maneira, o valor de localização nunca reduz o índice de importância, e sim acrescenta, quando ocorrerem condições favoráveis no meio, evitando que, por exemplo, a presença de fiação ou outro equipamento urbano seja um fator detrator de um espécime arbóreo, reduzindo seu valor. Ao valorizar a presença de outras árvores da mesma espécie próximas e a presença ou não de recuo, essa variável diminui a influência subjetiva do cadastrador na avaliação do local.

R. Árvore, Viçosa-MG, v.26, n. 5, p.629-642, 2002

\section{D) Valor biométrico (Vbm)}

$$
\mathrm{Vbm}=(\text { DAP } x \quad 0,6)+(\text { Hb } x \text { 0,4) }
$$

Valor biométrico: é a ponderação entre o diâmetro à altura do peito (DAP), peso de $60 \%$, e a altura da primeira ramificação $(\mathrm{Hb})$, peso de $40 \%$.

Essa ponderação é importante em vias públicas, devido à necessidade de a altura da primeira ramificação das árvores ser elevada para que pedestres e veículos não tenham espaços de circulação reduzidos pela copa das árvores. Porém ocorre variação no espaço lateral ocupado entre diferentes espécies, devido às características morfológicas, qualificadas por variações no crescimento meristemático, originando eixos principais de crescimento e causando variação na necessidade de altura da primeira ramificação.

Segundo Seitz (1996), um exemplo é a comparação entre Tabebuia roseo-alba (ipê-branco) e Delonix regia (flamboyant). A primeira possui ramificação dicotômica peculiar, produzindo galhos com direcionamento verticalizado, predominantemente para o alto, ocupando menor espaço lateral; já a espécie $D$. regia possui maior crescimento no sentido horizontal, ocupando maior espaço lateral e necessitando de uma altura de copa e primeira ramificação mais elevada, podendo condicionar maior freqüência de serviços de poda. Essa variação deve ser avaliada no item (A), em partes desejáveis.

\section{E) Freqüência (Freq)}

Freq = é a freqüência de indivíduos de uma espécie na arborização, em porcentagem.

\subsubsection{Valor Monetário do Indivíduo Arbóreo}

Com o cálculo do Iir, o banco de dados transformará esse valor em moeda corrente, multiplicando o Iir de cada indivíduo arbóreo por uma constante. A constante é calculada a partir da equivalência do Iir da menor árvore jovem da espécie mais comum na arborização, cadastrada no banco de dados, ao seu custo total de plantio.

Para elaboração do custo, fornecido pela Prefeitura de Jaboticabal, observaram-se o preparo físico e químico do berço de plantio, sua proteção por meio da colocação de uma cinta de concreto, muda adquirida do viveiro municipal e a proteção da muda com tutoramento com bambu e gradil de madeira pintado com tinta látex e 
instalado a $0,50 \mathrm{~m}$ abaixo do nível do canteiro e com altura livre de $1,80 \mathrm{~m}$, possuindo nas quatro faces quatro sarrafos espaçados de $0,40 \mathrm{~m}$.

Quadro 2 - Custo de plantio de árvore em via pública, em Jaboticabal-SP

Table 2 - Cost of street tree planting in Jaboticabal-SP

\begin{tabular}{|c|c|}
\hline Componentes do Plantio & Valor $(\mathrm{R} \$)$ \\
\hline Calcário dolomítico & 0,0101 \\
\hline Adubo químico & 0,1558 \\
\hline Matéria orgânica & 0,5270 \\
\hline Cinta de proteção do canteiro & 4,0000 \\
\hline Muda (altura de $30 \mathrm{~cm}$ ) & 2,0000 \\
\hline Gradil de madeira & 3,1682 \\
\hline Revestimento gradil (tinta látex) & 1,2090 \\
\hline Reconstituição do pavimento do passeio & 0,9300 \\
\hline Total & 12,0000 \\
\hline
\end{tabular}

Iir $=0,03$ (menor valor encontrado no cadastro); custo de plantio $=$ $\mathrm{R} \$ 12,00$, então tem-se: Constante $\mathrm{Kr}=\mathrm{R} \$$ plantio / Iir (3); e $\mathrm{Kr}=$ $12 / 0,03=400,00$ é a constante para a cidade de Jaboticabal - SP.

\subsection{3. Índice de Riqueza de Espécies (d)}

Além das expressões de valor, o banco de dados vai produzir uma comparação entre as diversidades nos bairros da cidade cujas vias públicas foram cadastradas (Simpson, 1949). É dado por:

$$
\mathrm{d}=(S-1) / \log _{10} N(4)
$$

em que $\mathrm{d}=$ riqueza de espécies em cada bairro (bits por indivíduo); $S=$ número de espécies no bairro; e $N=$ número de indivíduos total no bairro.

\subsection{Elaboração do Banco de Dados}

Com base em Kaufeld (1996), Gerhold et al. (1987) e Thurman (1983), o banco de dados foi construído em Access, pela facilidade de manuseio, disponibilidade do sistema e baixa necessidade de recursos físicos por parte do computador operacional. A criação do aplicativo seguiu a seguinte seqüência:

a) Inicialmente, procedeu-se à elaboração das bibliotecas de informações, ao todo 36 tabelas, com a listagem de todas as ruas, bairros, gêneros, famílias botânicas, espécies e outros dados, como cor da flor, origem da espécie, serviços recomendados, tipo de pavimento e tipo de propagação. b) Após essa etapa, procedeu-se à construção das duas tabelas ou entidades básicas intituladas "biblioteca de espécies" e "tabela-mestre". A última contém todos os atributos para o cadastro do indivíduo e do local, contendo todos os itens da ficha de cadastro manual (Quadro 1).

c) Na etapa seguinte, procedeu-se à construção dos relacionamentos, para transformação de dados biométricos como altura da primeira ramificação, perímetro à altura do peito, diâmetro da copa, altura da árvore e freqüência de cada espécie arbórea no cadastro, obtendo-se os índices de valor e diversidade, conforme apresentado na Figura 1. Estes relacionamentos e as tabelas de dados (Entidades) foram projetados com base nos modelos de banco de dados descritos em Dalcin (1992a, 1994).

d) Após essa etapa, elaborou-se também a consulta auxiliar de dados, como total de indivíduos por espécie, total de área de copa, total de árvores com problemas de sanidade, total de árvores com injúrias mecânicas e árvores sob fiação.

e) Na seqüência, foram elaboradas as interfaces para entrada de dados, visualização de fotos das árvores (hiperlink), gráficos e relatórios com valores das árvores, diversidade entre os bairros e listagens de serviços recomendados: podas, remoções, plantios e demais controles.

f) Por fim, foram confeccionados macros, fazendo ligações funcionais entre os formulários de consulta e formulários de trabalho, gráficos e relatórios.

\section{RESULTADOS E DISCUSSÃO}

\subsection{Apresentação da Interface}

A interface amigável apresenta sete formulários, um principal e seis com controles que conduzem o usuário às tabelas, aos gráficos e às listagens propostas (Figura 2).

Essas telas otimizam a coleta de informações, evitando perda de tempo com digitações ou atualizações dispendiosas.

As fotos digitais são visualizadas por meio de um campo do tipo hiperlink. Desta maneira, cada ficha contém dados do indivíduo arbóreo, sua foto e a opção de detalhamento para observação de alguma injúria ou característica marcante. Estas fotos são gravadas em arquivos tipo ".jpg", objetivando economia de espaço em disco rígido.

R. Árvore, Viçosa-MG, v.26, n.5, p.629-642, 2002 


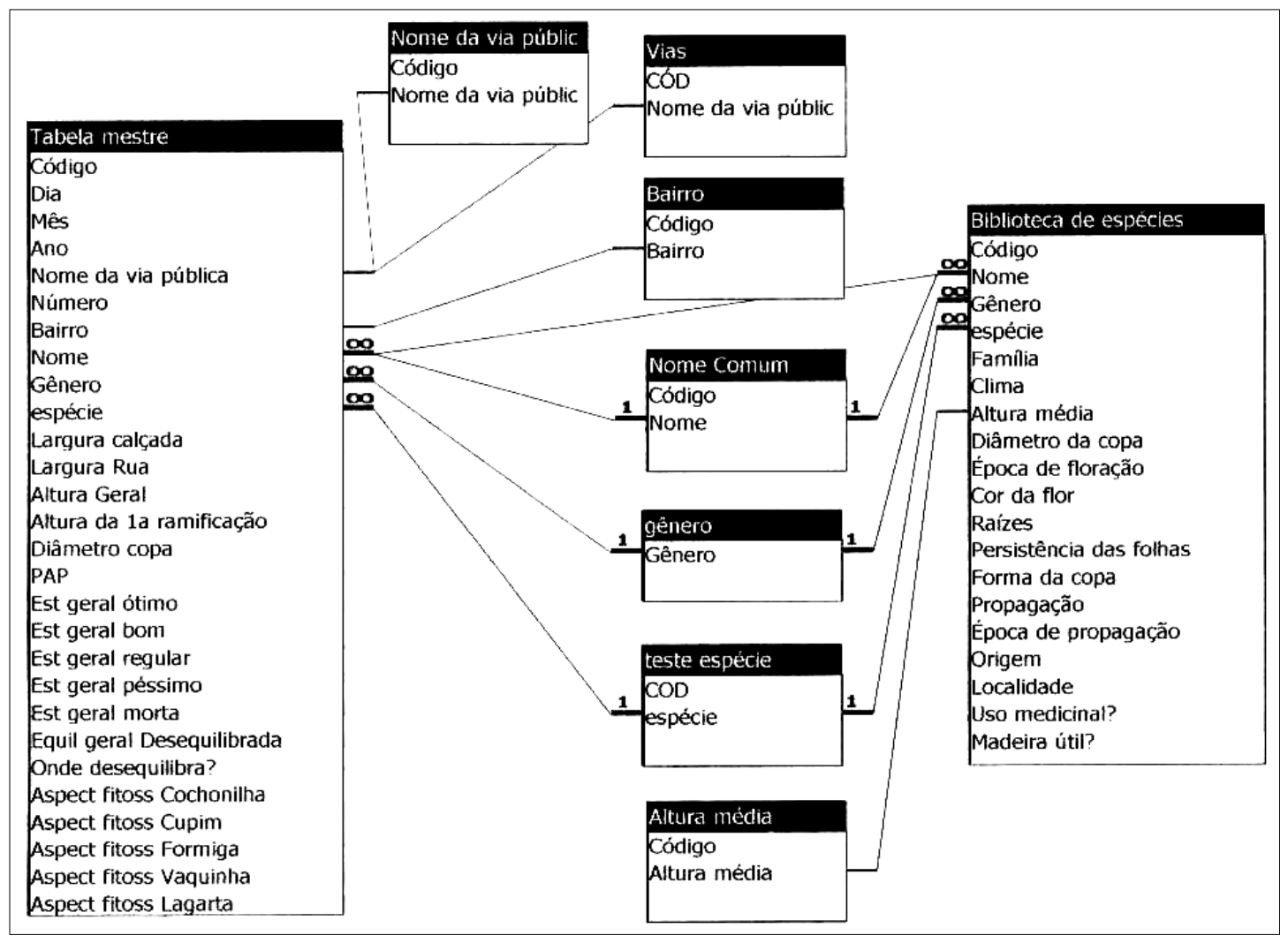

Figura 1 - Relacionamentos (linhas de ligação) entre as entidades ou tabelas como um diagrama de modelo Entidades Relacionamentos (diagrama E-R).

Figure 1 -Relationships (connection lines) among the entities or tables as a diagram of model Entities - Relationships (E-R diagram).

\subsection{Consultas de Serviços de Manutenção}

O sistema foi elaborado para fornecer consultas prontas de fácil acesso, como listagens de árvores para serem podadas, ampliação de canteiros, substituições e listagens gerais de todas as árvores cadastradas, podendo ser impressas ou visualizadas (Figura 3). Outras consultas podem ser feitas em pesquisas de referência cruzada para visualização de diferentes situações.

\subsection{Avaliação dos Resultados}

Segundo Odum (1988), o conceito de diversidade de espécies possui dois componentes: 1) riqueza, também chamada de densidade de espécies, baseada no número de espécies presentes; e 2) uniformidade, baseada na abundância relativa (ou em outra medida de "importância") de espécies e no grau da sua dominância ou falta desta.
É de extrema importância o conhecimento desses dois componentes que conceituam a diversidade, pois o índice em si apenas serve para comparação com outras amostras de outras áreas (Guzzo, 1991).

Segundo Pinto - Coelho (2000), a diversidade biológica pode ser acessada mediante o uso de diferentes índices e modelos estatísticos. O uso desses índices, contudo, é restrito, pois todos apresentam limitações que impõem um elevado conhecimento ecológico do sistema em foco.

O índice (d) expressa a diversidade, mostrando a densidade, não evidenciando completamente as características de uniformidade ou dominância de espécies, que é expressa no índice de importância relativa (Iir). Na cidade de Jaboticabal o valor (d) é 12,98.

Guzzo (1991) utilizou o índice de Brillouin para mensurar a diversidade na arborização das vias públicas do bairro Jardim Procópio em Ribeirão Preto-SP. 

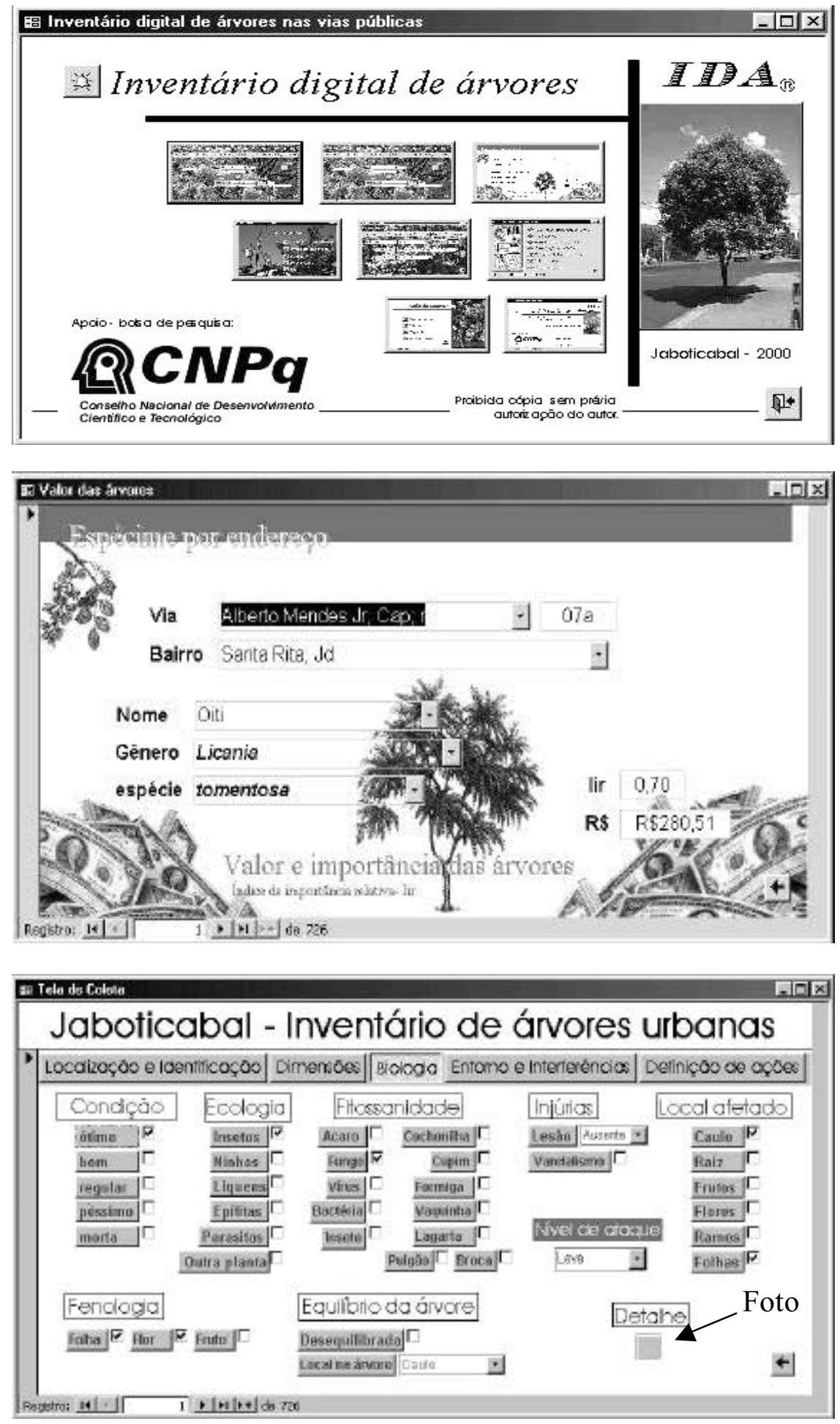

Figura 2 - Telas referentes ao formulário principal (acima), ao formulário dos valores das árvores cadastradas e à parte do formulário para a coleta de dados (abaixo).

Figure 2 - The main form (left screen), tree value form and "Screen Collection" (below). 


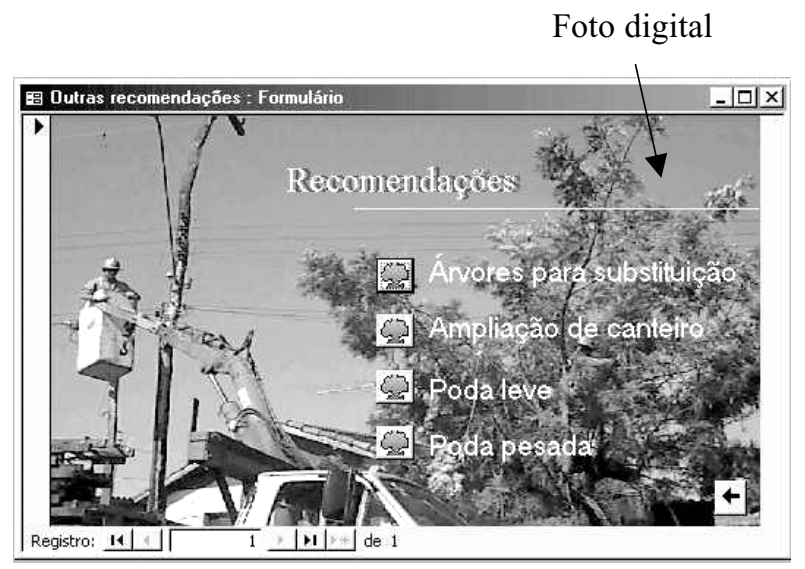

Figura 3 - O formulário "Recomendações" e os botões, amigabilidade.

Figure 3 -Friendly' user Recomendation form and buttons.

Com o cadastro completo existe a possibilidade de comparar os diversos valores do índice (d), estabelecer relações com outros fatores e planejar intervenções para o incremento da diversidade. Nos bairros de Jaboticabal, o índice (d) está variando conforme o Quadro 3.

Ao efetuar a consulta seletiva das populações arbóreas no banco de dados de Jaboticabal-SP, com relação aos plantios recentes, para obtenção da distribuição por freqüência das árvores jovens com altura inferior a $2 \mathrm{~m}$, nota-se a predominância de Licania tomentosa (Benth.)
Fritsch (oiti) com 39,69\% das árvores e 7,50\% de Murraya exotica L. (falsa-murta), mostrando uma tendência perigosa de perda da diversidade e riscos para arborização, principalmente quando estes plantios jovens sucederem as árvores mais velhas ou com problemas. Ocorreram, também, diminuição no número de espécies, de 108 (com $2 \mathrm{~m}$ ou mais) para 75 (abaixo de $2 \mathrm{~m}$ ), e um índice de diversidade (d) igual a 10,38.

Pode-se comparar a diversidade entre os bairros cadastrados, mas não é possível comparar com outros trabalhos, em outras cidades, pois não existe equivalência entre os índices utilizados até o momento.

Pode-se notar a maior diversidade ocorrendo no bairro Nova Jaboticabal $(9,42)$, seguido do Bairro X $(9,29)$, da Cidade Jardim $(8,36)$, do Centro $(8,26)$ e do Jardim das Rosas $(7,22)$.

Santos et al. (2001) consideraram o número de 82 espécies encontradas no inventário da Universidade de Santa Maria como uma alta diversidade, sem contudo terem utilizado índices de diversidade para avaliação.

Grey \& Deneke (1978) discorreram quanto à distribuição das freqüências relativas das espécies na arborização urbana, preconizando um valor máximo de 10 a 15\% para que uma espécie não tenha riscos relacionados à longevidade, por meio de declínio e ataque de pragas ou doenças.

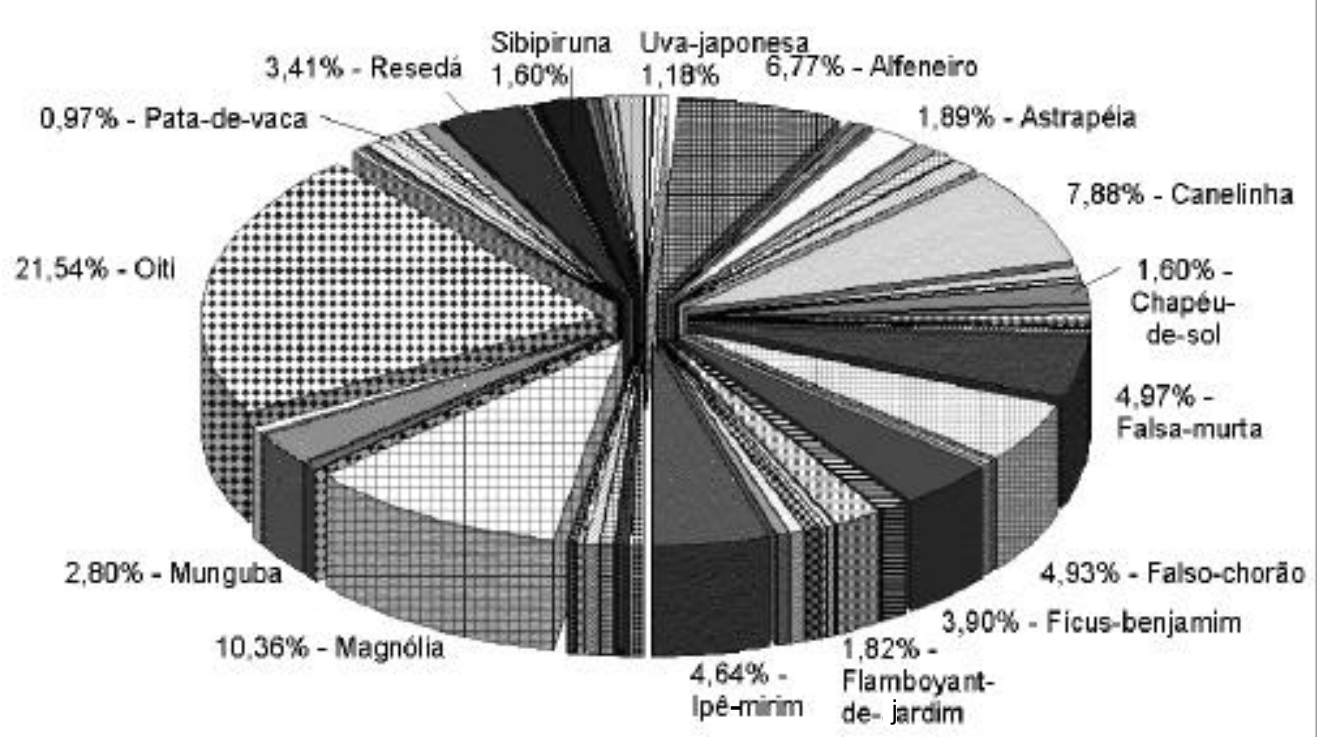

Figura 4 - Gráfico de distribuição das espécies na arborização de vias públicas.

Figure 4 - Urban street tree planting distribution. 
Quadro 3 - Índice de riqueza de espécies (d), em cada bairro de Jaboticabal - SP, e porcentagem com que as dez espécies mais freqüentes aparecem dentro de cada bairro e em relação ao total de plantas levantadas $(\mathrm{OI}=$ Oiti; MA = magnóliaamarela; $\mathrm{AL}=$ alfeneiro; $\mathrm{CA}=$ canelinha; $\mathrm{FC}=$ falso-chorão; $\mathrm{FM}=$ falsa-murta; $\mathrm{IM}=$ ipê-mirim; $\mathrm{RE}=$ resedá; $\mathrm{FB}=$ ficus-benjamina; $\mathrm{MU}=$ munguba; $\mathrm{OU}=$ outras)

Table 3 - Index of species varieties (d), in each neighborhood of Jaboticabal - SP, and percentage of the 10 most frequent species inside each neighborhood and in relation to the total assessed plants. (OI = "Oiti"; $M A=$ "Magnólia-amarela"; $A L$ = "Alfeneiro"; $C A=$ "Canelinha"; $F C=$ "Falso-chorão"; $F M=$ "Falsa-murta"; IM = "Ipê-mirim"; RE = "Resedá"; FB = "Ficus-benjamina"; $M U$ = "Munguba"; OT = "others")

\begin{tabular}{|c|c|c|c|c|c|c|c|c|c|c|c|c|}
\hline Bairro & $\mathrm{d}$ & OI & MA & $\mathrm{CA}$ & $\mathrm{AL}$ & $\mathrm{FC}$ & FM & IM & $\mathrm{RE}$ & FB & $\mathrm{MU}$ & $\mathrm{OU}$ \\
\hline Aparecida & 3,97 & 14,71 & 2,94 & 8,82 & 11,76 & 17,65 & - & 2,94 & 5,88 & - & - & 35,29 \\
\hline Bairro X & 9,29 & 15,31 & 13,48 & 4,63 & 7,58 & 1,69 & 3,79 & 6,18 & 3,79 & 2,67 & 5,90 & 34,97 \\
\hline Bela Vista, Jardim & 2,42 & 5,56 & 33,33 & 5,56 & 22,22 & 5,56 & - & 11,11 & - & - & - & 16,67 \\
\hline Brandi, Jardim & 4,92 & 43,65 & 8,63 & 3,55 & 3,05 & 6,09 & 4,57 & 1,02 & - & 1,02 & 1,02 & 27,41 \\
\hline Bueno Aires, Vila & 4,55 & 11,90 & - & - & - & 26,19 & - & 9,52 & - & - & - & 52,38 \\
\hline Centro & 8,26 & 20,65 & 10,32 & 5,28 & 5,91 & 6,54 & 7,09 & 8,43 & 2,99 & 3,47 & 1,97 & 27,34 \\
\hline Cidade Alta & 1,47 & 11,67 & - & - & - & - & - & - & - & 45,00 & - & 43,33 \\
\hline Cidade Jardim & 8,36 & 20,90 & 5,79 & 8,68 & 1,93 & 3,86 & 1,29 & 12,86 & 8,68 & 2,57 & 2,25 & 31,19 \\
\hline Cohab 2 & 4,19 & 24,14 & 15,52 & 10,34 & 8,62 & 3,45 & 1,72 & - & - & - & 15,52 & 20,69 \\
\hline das Rosas, Jardim & 7,23 & 35,93 & 6,59 & 5,69 & 0,90 & 5,99 & 4,19 & 2,40 & 6,89 & - & 5,39 & 26,05 \\
\hline Grajaú, Jardim & 6,69 & 26,19 & 9,52 & 14,29 & 7,48 & 3,74 & 4,76 & 3,40 & 3,74 & 0,34 & 2,72 & 23,81 \\
\hline Guanabara, Jardim & 3,11 & 38,89 & 5,56 & - & - & 5,56 & - & 5,56 & - & - & - & 44,44 \\
\hline Hugo L. Vitali & 4,12 & 8,59 & 32,03 & 5,47 & 27,34 & 3,91 & 1,56 & - & 6,25 & - & - & 14,84 \\
\hline Independência, Jardim & 2,80 & 16,00 & 32,00 & 12,00 & - & 4,00 & 8,00 & - & - & - & - & 28,00 \\
\hline Isabel, Vila & 4,54 & 14,71 & - & 2,94 & 5,88 & - & 8,82 & - & 8,82 & - & - & 58,82 \\
\hline Kennedy, Jardim & 5,88 & 18,61 & 18,98 & 8,39 & 5,47 & 2,92 & 5,11 & 2,55 & 7,30 & 0,73 & 3,28 & 26,64 \\
\hline Margarida Berchieri & 7,03 & 17,23 & 12,16 & 21,62 & 8,78 & 4,73 & 2,03 & 1,01 & 3,04 & 0,68 & 2,03 & 26,69 \\
\hline Mônica, Sta; Jardim & 4,77 & 18,80 & 5,98 & 23,08 & 12,39 & 5,98 & 3,85 & 1,71 & 8,12 & 1,28 & 2,56 & 16,24 \\
\hline Morumbi, Jardim & 6,44 & 25,33 & 9,17 & 0,44 & 4,80 & 4,37 & 11,35 & 3,49 & 2,18 & 3,06 & 0,87 & 34,93 \\
\hline Nova Aparecida & 5,23 & 24,69 & 16,05 & 2,47 & 9,88 & 1,23 & 1,23 & - & - & - & 3,70 & 40,74 \\
\hline Nova Jaboticabal & 9,42 & 15,90 & 9,23 & 3,76 & 9,23 & 7,01 & 8,72 & 4,10 & 1,88 & 9,40 & 2,05 & 28,72 \\
\hline Paulista, Jardim & 2,51 & 16,67 & - & 5,56 & 55,56 & 2,78 & - & 2,78 & 2,78 & - & 2,78 & 11,11 \\
\hline Pedroso, Jardim & 4,37 & 22,08 & 5,19 & 18,18 & 2,60 & 3,90 & - & 10,39 & 6,49 & - & 2,60 & 28,57 \\
\hline Planalto Itália & 5,82 & 35,21 & 8,80 & 14,18 & 2,69 & 4,40 & 4,16 & 2,93 & 1,47 & - & 1,22 & 24,94 \\
\hline Primavera, Jardim & 4,51 & 14,50 & 3,05 & 25,95 & 3,05 & 3,05 & 0,76 & - & 12,98 & - & 6,87 & 29,77 \\
\hline Royal, Parque & 2,04 & - & - & - & - & - & 16,13 & - & 3,23 & 29,03 & - & 51,61 \\
\hline Santa Luzia & 4,82 & 32,20 & 10,17 & 2,54 & 16,10 & 2,54 & 5,93 & 3,39 & 5,08 & 0,85 & - & 21,19 \\
\hline Santa Rita, Jardim & 6,49 & 22,66 & 17,58 & 3,13 & 5,47 & 3,52 & 5,47 & 4,30 & 1,17 & 5,08 & 4,30 & 27,34 \\
\hline Santa Teresa & 3,86 & 34,92 & - & 9,52 & 12,70 & 3,17 & 4,76 & - & 1,59 & - & 1,59 & 31,75 \\
\hline Sena, Vila & 3,82 & 16,67 & - & - & - & 6,67 & - & - & - & 10,00 & - & 66,67 \\
\hline Sorocabano & 7,02 & 24,34 & 7,68 & 9,43 & 7,68 & 6,58 & 3,29 & 5,04 & 4,82 & 2,85 & 3,51 & 24,78 \\
\hline Tangará, Jardim & 6,18 & 1,91 & 12,44 & 2,39 & 2,87 & 6,22 & 5,26 & 0,96 & 4,78 & 12,92 & 1,44 & 48,80 \\
\hline Verde Ville & 1,82 & 11,11 & - & - & - & - & 11,11 & 11,11 & - & 44,44 & - & 22,22 \\
\hline Total* & 12,98 & 21,54 & 10,36 & 7,88 & 6,77 & 4,97 & 4,93 & 4,64 & 3,90 & 3,41 & 2,80 & 28,89 \\
\hline
\end{tabular}

* apenas o índice de riqueza não é expresso em porcentagem em relação ao total, refletindo a diversidade em cada bairro e na cidade em bits por indivíduo. 
Quadro 4 - Listagem das 30 primeiras espécies, organizadas por ordem de valor monetário, com seus respectivos índices e valores médios. $\left(\mathrm{Ii}=\right.$ índice de importância; Iir = índice de importância relativa; área-copa $=$ projeção da copa $\left(\mathrm{m}^{2}\right)$; e média-R $\$$ = valor em moeda corrente)

Table 4 - First thirty species listed, organized by cost value, and their respective indexes and medium values. $\left(\right.$ I $i=$ importance index; Iir $=$ relative importance index; canopy-area $=$ canopy projection $\left(m^{2}\right) ; \operatorname{Medium}-R \$=m e d i u m$ currency monetary value)

\begin{tabular}{|c|c|c|c|c|c|c|}
\hline Gênero & Espécie & Nome Comum & Ii & Iir & Área-Copa & Média (R\$) \\
\hline Pterygota & brasiliensis Allemão & Pau-rei & 25,21 & $1.779,02$ & 33,17 & $711.609,46$ \\
\hline Guazuma & ulmifolia Lam. & Mutambu & 24,93 & $1.759,88$ & 107,46 & $703.953,82$ \\
\hline Stifftia & chrysantha Mikan & Diadema & 16,75 & $1.182,05$ & 1,13 & $472.821,09$ \\
\hline Roystonea & oleracea (Jacq.) O.F. Cook & Palmeira imperial & 31,68 & $1.118,08$ & - & $447.233,31$ \\
\hline Syzygium & jambolana DC. & Jambo & 15,05 & $1.061,90$ & 23,75 & $424.760,60$ \\
\hline Caesalpinia & echinata Lam. & Pau-brasil & 48,62 & 857,97 & 45,43 & $343.187,23$ \\
\hline Koelreuteria & paniculata Laxm. & Lanterna-japonesa & 10,91 & 769,97 & 0,35 & $307.988,04$ \\
\hline Cassia & grandis L.f. & Cassia-rosa & 43,52 & 767,82 & 103,81 & $307.129,32$ \\
\hline Peltophorum & dubium Taub. & Canafistula & 20,62 & 727,51 & 110,39 & $291.003,56$ \\
\hline Camellia & japonica $\mathrm{L}$. & Camelia & 8,66 & 610,97 & 3,14 & $244.388,01$ \\
\hline Tibouchina & pulchra Cogn. & Manacá-da-serra & 14,93 & 526,95 & 0,13 & $210.778,52$ \\
\hline Erythrina & speciosa Andrews & Eritrina & 13,47 & 475,44 & 3,53 & $190.176,61$ \\
\hline Machaerium & aculeatum Raddi & Jacarandá-bico-de-pato & 6,49 & 458,20 & 18,09 & $183.279,13$ \\
\hline Tabebuia & impetiginosa (Mart.) Standl. & Ipê-roxo-pequeno & 18,69 & 439,65 & 60,43 & $175.859,26$ \\
\hline Ficus & lyrata Warb. & Figueira & 5,81 & 410,01 & 0,82 & $164.004,84$ \\
\hline Copaifera & langsdorffii Desf. & Óleo-bálsamo & 9,71 & 342,66 & 83,95 & $137.064,57$ \\
\hline Dillenia & indica $\mathrm{L}$. & Maçã-elefante & 8,86 & 312,77 & 2,41 & $125.107,18$ \\
\hline Grevillea & robusta A. Cunn. & Grevilha & 8,67 & 305,99 & 17,76 & $122.395,59$ \\
\hline Albizia & hasslerii (Chodat) Burkart & Farinha-seca & 11,88 & 279,60 & 135,28 & $111.838,85$ \\
\hline Balfourodendron & riedelianum Engl. & Pau-marfim & 15,53 & 274,06 & 26,81 & $109.625,76$ \\
\hline Bougainvillea & spectabilis Willd. & Primavera & 3,67 & 259,19 & 0,79 & $103.676,25$ \\
\hline Lophanthera & lactescens Ducke & Lofântera & 3,55 & 250,42 & 0,07 & $100.169,29$ \\
\hline Jacaranda & mimosaefolia D. Don & Jacarandá-mimoso & 9,79 & 230,35 & 18,06 & $92.140,62$ \\
\hline Colubrina & glandulosa Perkins & Saguaragi & 9,77 & 229,77 & 5,79 & $91.907,61$ \\
\hline Triplaris & brasiliana Cham. & Pau-formiga & 6,23 & 220,00 & 15,70 & $87.998,47$ \\
\hline Bombacopsis & glabra (Pasq.) A. Robyns & Castanha-do-maranhão & 8,88 & 208,90 & 9,96 & $83.558,57$ \\
\hline Caryota & urens $\mathrm{L}$. & Palmeira rabo-de-peixe & 2,95 & 207,98 & - & $83.192,31$ \\
\hline Grevillea & banksii $\mathrm{R}$. Br. & Grevilha-anã & 11,18 & 197,27 & 17,13 & $78.907,89$ \\
\hline Polyscias & $\begin{array}{l}\text { fiscifolia (C. Moore ex E. } \\
\text { Fourn.) L. H. Bailey }\end{array}$ & Árvore-da-felicidade & 5,33 & 188,12 & 11,48 & $75.249,26$ \\
\hline Adenanthera & pavonina $\mathrm{L}$. & Tento-carolina & 26,49 & 186,95 & 21,06 & $74.778,18$ \\
\hline Inga & uruguensis Hook. et Arn. & Ingá & 5,27 & 186,02 & 24,54 & $74.407,12$ \\
\hline Eugenia & pyriformis Cambess. & Uvaia & 5,03 & 177,51 & 15,90 & $71.005,66$ \\
\hline
\end{tabular}

Deve-se utilizar, no mínimo, de sete a dez diferentes espécies para compor a arborização de uma cidade, sendo um número entre 10 e 20 bastante recomendável (Milano \& Dalcin, 2000).

$\mathrm{Na}$ Figura 4, nota-se a dominância das espécies Licania tomentosa (oiti) $(21,54 \%)$ e Michelia champaca L. (magnólia amarela) $(10,36 \%)$ para a arborização de vias públicas do município de Jaboticabal-SP, indicando boa distribuição em relação a outras cidades onde a arborização é constituída por apenas uma ou duas espécies.

Rolim \& Nascimento (1997) demonstraram que o índice de Shannon pouco variou nas diferentes intensidades amostrais, em uma comunidade arbórea tropical. 
Existe também uma grande irregularidade na distribuição das espécies dentro dos bairros (Quadro 3), o que dificulta a execução de serviços de manutenção que poderiam ser locados mediante a necessidade particular de uma espécie, mas, por causa edessa irregularidade, podem apresentar dificuldades para serem planejados adequadamente.

Existem árvores que se destacam na arborização pelo tamanho ou pela raridade ou por estarem bem localizadas e serem adaptadas às condições de vias públicas. O sistema, utilizando o índice de importância relativa (Iir), encontra tais espécies e valoriza sua existência na arborização. Esse fato pode ser amplamente divulgado no município do cadastro, por meio da utilização do banco de dados como fonte de informação para escolas públicas e programas de educação ambiental, possibilitando a adequação do trabalho para utilização didática como vetor de comunicação, como descrito por Pegoraro \& Sorrentino (1998), possibilitando o aumento da intimidade da população com as árvores de rua. Os estudantes e demais munícipes poderiam ter acesso aos dados como fotos e localização das árvores, aprender sobre cada espécie e, desta maneira, passar a melhor valorizar as árvores.

No Quadro 4, a média de Iir por espécie ilustra altos valores para algumas espécies, expressando sua raridade na população.

O Quadro 4 ilustra a situação em que espécies com baixa freqüência na arborização ganham destaque com altos valores, como a Guazuma ulmifolia (mutambu), Stifftia chrysantha (diadema) e Pterygota brasiliensis (pau-rei), para arborização de Jaboticabal-SP.

As espécies podem ser objeto de seleção, sendo seus indivíduos proeminentes (com índice superior) eleitos como matrizes, bastando, para isso, uma consulta ao sistema, que mostrará as fichas e os índices em ordem crescente de valor. Caso a prefeitura deseje utilizar árvores de grande porte, em espaços adequados, poderá eleger matrizes entre indivíduos situados em locais pouco adequados, mas que apresentem condições de destaque fitossanitário e estético.

É interessante para a conservação genética que outras cidades adotem princípios semelhantes de avaliação de matrizes e possam trocar sementes para evitar endogamia, muito embora existam problemas como o desconhecimento da origem parental.

Godfrey (2001) associou cadastros da arborização urbana com sistemas de informações geográficas. O presente aplicativo será objeto de ampliações para suportar geoprocessamento, possibilitando visualização espacial do cadastro. Esta atividade está sendo implementada no município de Jaboticabal-SP, assim como em várias localidades brasileiras, como as cidades de São Paulo, São Carlos e Recife, como descrito em Freire et al. (1994) e Oliveira \& Santos (1997).

\section{CONCLUSÃO}

O uso do banco de dados relacional para arborização de vias públicas é de grande importância, pois:

a) Fornece informações sobre o entorno onde o indivíduo arbóreo está inserido e a porcentagem de árvores sob fiação, árvores em contato com algum tipo de fiação, árvores com afloramento de raízes, construções com recuo e árvores sem equilíbrio, entre outras.

b) Com esse método é possível realizar pesquisas por espécie, bairro ou rua e, além disto, cruzar informações, buscando relações, como saber a quantidade de árvores desequilibradas que apresentam lesão ou comparar a população com problemas fitossanitários e a incidência de podas drásticas.

c) É uma aplicação prática da informática, fornecendo resultados sobre a valoração de indivíduos cadastrados, diversidade nos bairros e na cidade, possibilidade de introdução de fotos digitais, diversificados relatórios para manejo e auxílio ao cadastramento das árvores por meio de interface amigável.

\section{REFERÊNCIAS BIBLIOGRÁFICAS}

DALCIN, E. C. Manejo Informatizado da arborização urbana e coleções botânicas vivas. In: CONGRESSO BRASILEIRO SOBRE ARBORIZAÇÃO URBANA, 1., 1992, Vitória. Anais... Vitória: PMV/SMMA, 1992a. p. 125-132.

DALCIN, E. C. Índice de importância relativa (IIr) e valor da espécie (Ve): Proposta de uma fórmula para avaliar exemplares arbóreos na arborização urbana. In: CONGRESSO BRASILEIRO SOBRE ARBORIZAÇÃO URBANA, 1., 1992b, Vitória. Anais... Vitória: PMV/ SMMA, 1992b. p. 291-305.

DALCIN, E. C. A informática no inventário e monitoramento da arborização urbana. In: CONGRESSO BRASILEIRO SOBRE ARBORIZAÇÃO URBANA, 2., 1994, São Luís. Anais... São Luís: Sociedade Brasileira de Arborização Urbana, 1994. p. 201-206.

R. Árvore, Viçosa-MG, v.26, n.5, p.629-642, 2002 
FREIRE , F. J. et al. Cadastramento das árvores públicas da cidade do recife utilizando o sistema de informações geográficas (GIS). In: CONGRESSO BRASILEIRO SOBRE ARBORIZAÇÃO URBANA, 2., 1994, São Luís. Anais... São Luís: Sociedade Brasileira de Arborização Urbana, 1994. p. 431-436.

GERHOLD, H. D.; STEINER, K. C.; SACKSTEDER, C. J. Management information systems for urban trees. Journal of Arboriculture, n. 13, p. 243-249, 1987.

GODFREY, C. G. GIS \& GPS in urban forestry. City Trees, v. 37, n. 3, p. 14-16, 2001.

GRAZIANO, T. T.; CASTIGLIONI, F. M.; VASQUES, L. $H$. Caracterização e análise da arborização das ruas do município de Jaboticabal, SP. Jaboticabal: UNESP-FCAV, 1987. $12 \mathrm{p}$.

GREY, G. W.; DENEKE, F. J. Urban forestry. New York: John Wiley, 1978. $279 \mathrm{p}$.

INSTITUTO BRASILEIRO DE GEOGRAFIA E ESTATÍSTICA - IBGE. (Disponível em: http:// www.ibge.hpg.gov.br, 30/11/2000).

KAUFELD, J. Access 95 para Windows para leigos: Um manual para novos usuários. LUDEMIR, J. São Paulo: Berkeley Brasil, 1996. 352 p.

MILANO, M. S.; DALCIN, E. C. Arborização de vias públicas. Rio de Janeiro: Light, 2000. 226 p.

ODUM, E. P. Ecologia. Rio de Janeiro: Guanabara, 1988. $434 \mathrm{p}$.

OLIVEIRA, C. H.; SANTOS, J. E. Avaliação e proposta de política de áreas verdes de São Carlos, SP: uma abordagem com emprego de Sistema de Informações Geográficas. In: ENCONTRO NACIONAL SOBRE ARBORIZAÇÃO URBANA, 7., 1997, Belo Horizonte. Anais... Belo Horizonte: CEMIG, 1997. p. 21.
PEGORARO, J. L.; SORRENTINO, M. Programas educativos com flora e fauna (expressões da biodiversidade) e a educação ambiental. Scientia Florestalis, n. 54, p. 131142, 1998.

PINTO-COELHO, R. M. Fundamentos em ecologia. Porto Alegre, RG: Artes Médicas Sul, 2000. 247 p.

ROLIM, S. G.; NASCIMENTO, H. E. M. Análise da riqueza, diversidade e relação espécie-abundância de uma comunidade arbórea tropical em diferentes intensidades amostrais. Scientia Florestalis, n. 52, p. 7-16, 1997.

SANTOS, N. R. Z. et al. Análise da arborização do campus da Universidade Federal de Santa Maria (RS). In: ENCONTRO NACIONAL DE ARBORIZAÇÃO URBANA, 9., 2001, Brasília. Anais... SBAU, 2001. (CDROM)

FUNDAÇÃO SISTEMA ESTADUAL DE ANÁLISE DE DADOS - SEADE. (Disponível em: http:// www.seade.gov.br, 30/11/1999).

SEITZ, R. A. A poda de árvores urbanas. Curitiba: FUPEF, 1996. 41 p. (Série Técnica, 19)

SIMPSON, E. H. Measurement of diversity. Nature, v. 163, n. $688,1949$.

TAKAHASHI, L. Y. Monitoramento e informatização da administração e manejo da arborização urbana. In: CONGRESSO BRASILEIRO SOBRE ARBORIZAÇÃO URBANA, 1., 1992, Vitória. Anais... Vitória: PMV/SMMA, 1992. p. 119-124.

THURMAN, P. W. The management of urban street trees using computerised inventory systems. Arboricultural Journal, v. 7, p. 101-117, 1983. 